\title{
Application of Laser Induced Electron Impact Ionization to the Deposition Chemistry in the Hot-Wire Chemical Vapor Deposition Process with $\mathrm{SiH}_{4}-\mathrm{NH}_{3}$ Gas Mixtures
}

\author{
Brett Eustergerling, Martin Hèden, and Yujun Shi \\ Department of Chemistry, University of Calgary, Calgary, Alberta, Canada
}

\begin{abstract}
The application of a laser-induced electron impact (LIEI) ionization source in studying the gas-phase chemistry of the $\mathrm{SiH}_{4} / \mathrm{NH}_{3}$ hot-wire chemical vapor deposition (HWCVD) system has been investigated. The LIEI source is achieved by directing an unfocused laser beam containing both $118 \mathrm{~nm}(10.5 \mathrm{eV})$ vacuum ultraviolet (VUV) and $355 \mathrm{~nm}$ UV radiations to the repeller plate in a time-of-flight mass spectrometer. Comparison of the LIEI source with the conventional $118 \mathrm{~nm}$ VUV single-photon ionization (SPI) method has demonstrated that the intensities of the chemical species with ionization potentials (IP) above $10.5 \mathrm{eV}$, e.g., $\mathrm{H}_{2}, \mathrm{~N}_{2}$ and $\mathrm{He}$, have been significantly enhanced with the incorporation of the LIEI source. It is found that the SPI source due to the $118 \mathrm{~nm}$ VUV light coexists in the LIEI source. This allows simultaneous observations of parent ions with enhanced intensity from VUV SPI and their "fingerprint" fragmentation ions from LIEI. It is, therefore, an effective tool to diagnose the gas-phase chemical species involved with both $\mathrm{NH}_{3}$ and $\mathrm{SiH}_{4}$ in the HWCVD reactor. In using the LIEI source to $\mathrm{SiH}_{4}, \mathrm{NH}_{3}$ and their mixtures, it has been shown that the $\mathrm{NH}_{3}$ decomposition is suppressed with the addition of $\mathrm{SiH}_{4}$ molecules. Examination of the $\mathrm{NH}_{3}$ decomposition percentage and the time to reach the $\mathrm{N}_{2}$ and $\mathrm{H}_{2}$ steady-state intensities for various $\mathrm{NH}_{3} / \mathrm{SiH}_{4}$ mixtures suggests that the extent of the suppression is enhanced with more $\mathrm{SiH}_{4}$ content in the mixture. With increasing filament temperatures, the negative effect of $\mathrm{SiH}_{4}$ becomes less important. (J Am Soc Mass Spectrom 2007, 18, 1950-1958) (c) 2007 American Society for Mass Spectrometry
\end{abstract}

S ilicon nitride $\left(\mathrm{SiN}_{\mathrm{x}}\right)$ thin films, deposited by hotwire chemical vapor deposition (HWCVD) methods at low substrate temperatures, have attracted increasing research interest owing to their wide range of applications, such as anti-reflection coatings, passivation layers, diffusion barriers, and gate insulators, in semiconductor and electronics industry [1,2]. The two simple hydrides, $\mathrm{SiH}_{4}$ and $\mathrm{NH}_{3}$, are the most widely used source gases for $\mathrm{SiN}_{\mathrm{x}}$ film formation using HWCVD. The deposition chemistry from $\mathrm{SiH}_{4}$ has been extensively studied in light of its use as the source gas for silicon thin-film deposition [3, 4]. At the high filament temperatures typical of Si film deposition, Si and $\mathrm{H}$ atoms are the primary species desorbed from the filament [5]. The gas-phase reactions of the two primary radicals with ambient silane molecules produce the final mix of depositing precursors such as $\mathrm{SiH}_{3}$ and $\mathrm{Si}_{2} \mathrm{H}_{2 \mathrm{y}}(\mathrm{y}=1-3)$ [6-9]. Ammonia decomposition chemistry, using tungsten metal in particular, has been studied since the early days of heterogeneous catalysis [10]. In studying the ammonia plasma processing of

Address reprint requests to Dr. Yujun Shi, Department of Chemistry, University of Calgary, Calgary, Alberta T2N 1N4, Canada. E-mail: shiy@ucalgary.ca metal and polymer substrates, Butoi et al. demonstrated that $\mathrm{NH}_{2}$ radicals are generated at the substrate surfaces [11]. Recently, Umemoto and coworkers studied the decomposition of $\mathrm{NH}_{3}$ on a hot tungsten filament [12]. They identified $\mathrm{H}$ atom and $\mathrm{NH}_{2}$ radical as primary products of ammonia decomposition. Two important stable products, $\mathrm{H}_{2}$ and $\mathrm{N}_{2}$, were observed using mass spectrometry.

Although knowledge of the HWCVD processes with two components has been obtained, details of gas-phase chemistry involved with $\mathrm{SiH}_{4}-\mathrm{NH}_{3}$ gas mixtures have been much less studied and, consequently, a full understanding has not yet been achieved. Using deuterated silane $\left(\mathrm{SiD}_{4}\right)$ as a source gas, Stannowski et al. [13] has shown that $\mathrm{SiH}_{4}$ is dissociated effectively at the filaments, whereas $\mathrm{NH}_{3}$ is scarcely dissociated at the filaments but rather in the gas phase by secondary reactions. Later, Umemoto et al. [14] reported a study on the deposition chemistry in the HWCVD processes of $\mathrm{SiH}_{4} / \mathrm{NH}_{3}$ mixtures. The densities of $\mathrm{NH}, \mathrm{NH}_{2}, \mathrm{SiH}_{3}$ radicals as well as $\mathrm{H}_{2}, \mathrm{~N}_{2}$, and $\mathrm{NH}_{3}$ molecules were measured. It was found that the decomposition efficiency of $\mathrm{NH}_{3}$ on the filament surfaces decreases with the introduction of $\mathrm{SiH}_{4}$. Recently, in their study of the plasma chemistry with $\mathrm{SiH}_{4}-\mathrm{NH}_{3}$ system in the process 
of plasma-enhanced CVD, van den Oever et al. [15] have also shown that the densities of $\mathrm{N}, \mathrm{NH}$, and $\mathrm{NH}_{2}$ in the plasma decreased with increasing $\mathrm{SiH}_{4}$ flow. These studies agree with the fact that a high gas flow ratio of $\mathrm{NH}_{3}$ to $\mathrm{SiH}_{4}$, ranging from 2:1 to greater than $100: 1$, is needed to get silicon nitride thin films under practical deposition conditions $[16,17]$. To understand the interplay of two components in the $\mathrm{SiH}_{4} / \mathrm{NH}_{3}$ mixture and the gas-phase chemistry in the HWCVD process using the mixture, we have used laser ionization time-of-flight mass spectrometry (TOF MS) in this work to detect the gas-phase reaction products from a HWCVD reaction chamber using $\mathrm{SiH}_{4}, \mathrm{NH}_{3}$, and $\mathrm{SiH}_{4}$ / $\mathrm{NH}_{3}$ mixtures with different pressure ratios.

Virtually all species of interest produced in the HWCVD processes using $\mathrm{SiH}_{4}$ as a source gas have ionization potentials (IP) below $10.5 \mathrm{eV}$. Therefore, single-photon ionization (SPI) using $118 \mathrm{~nm}$ vacuum ultraviolet (VUV) laser radiation has proven to be a powerful technique for examining silane chemistry [6]. Our recent studies have shown that VUV SPI also works well with alkylsilane molecular systems in the HWCVD process $[18,19]$. However, many of the products predicted for the $\mathrm{NH}_{3}$ and $\mathrm{SiH}_{4} / \mathrm{NH}_{3}$ systems, notably $\mathrm{H}_{2}$ and $\mathrm{N}_{2}$, have IPs greater than $10.5 \mathrm{eV}$. A single VUV photon at $\lambda=118 \mathrm{~nm}$ cannot ionize them. As a result, a complementary ionization method that would both be capable of ionizing these species and be convenient to implement with a minimum of instrumental modification is highly desirable. Laser-induced electron ionization (LIEI) is an excellent complement to laser ionization [20, 21]. In this method, electron pulses are generated by laser-induced photoemission from a metal target. These photoelectrons are then accelerated in the electric field of the ion source of the TOF MS to ionize the sample molecules. Previous experiments have reported on directing the laser beam to the repeller plate [22], the extraction plate [23], or to a metal target placed in between the two plates $[24,25]$ in an existing TOF MS. Since the photoelectron energies typically exceed the energy of a single $118 \mathrm{~nm}$ photon $(10.5 \mathrm{eV})$, they should be suitable for ionizing all species with IP of either lower or greater than $10.5 \mathrm{eV}$. In this work, our investigation into the employment of LIEI-MS as an analytical tool in examining gas-phase silicon-nitride film deposition chemistry is reported. The experimental setup for dual ionization source with VUV SPI and LIEI is described. Results from the studies of $\mathrm{SiH}_{4}, \mathrm{NH}_{3}$, and $\mathrm{SiH}_{4} / \mathrm{NH}_{3}$ mixtures are presented to illustrate that incorporation of a LIEI source into the conventional laser-ionization system provides a convenient method of simultaneously observing signals of species ionized by both SPI and LIEI.

\section{Experimental}

The $118 \mathrm{~nm}$ VUV laser ionization/photoelectron ionization experiments are carried out in a linear TOF mass spectrometer (R. M. Jordan Co., Grass Valley, CA). A detailed description of the experimental setup using VUV SPI, including the ionization laser source, HWCVD reactor, and the TOF MS, has been reported previously [18, 19, 26]. Briefly, a HWCVD chamber is connected through a $0.15 \mathrm{~mm}$ diameter pinhole to the high-vacuum ionization chamber housing the TOF MS. A tungsten filament $(0.5 \mathrm{~mm}$ diameter, $10 \mathrm{~cm}$ length) is placed in the HWCVD reactor and is resistively heated by a DC power supply. The filament temperatures were measured by a two-color pyrometer (Chino Works, Carson, CA). Source gases were introduced into the reactor via a mass flow controller (MKS, type $1179 \mathrm{~A}$ ) and the pressure in the reactor (7 to 13 torr) was monitored by a capacitance manometer (MKS Baratron, type 626A, Wilmington, MA). The operating pressures in the ionization chamber and flight tube under these reactor conditions were $4.0 \times 10^{-6}$ torr and $1.4 \times 10^{-6}$ torr, respectively.

Figure 1 shows the schematic of the dual ionization source used in this work. In SPI mode, chemical species exiting the pinhole of the HWCVD reactor were ionized by a VUV laser beam at $118 \mathrm{~nm}$ in a nonresonant process. The $118 \mathrm{~nm}$ radiation was produced by frequency tripling the $355 \mathrm{~nm}$ UV output from an Nd-YAG laser (Spectra-Physics, LAB-170-10, Mountain View, CA) in a gas cell containing 190 torr of a phase-matched 10:1 Ar/Xe gas mixture. The $355 \mathrm{~nm}$ laser energy was kept at $20 \mathrm{~mJ} /$ pulse with a repetition rate of $10 \mathrm{~Hz}$. A lithium fluoride (LiF) lens was inserted into the optical path after the gas cell to focus the $118 \mathrm{~nm}$ light at the

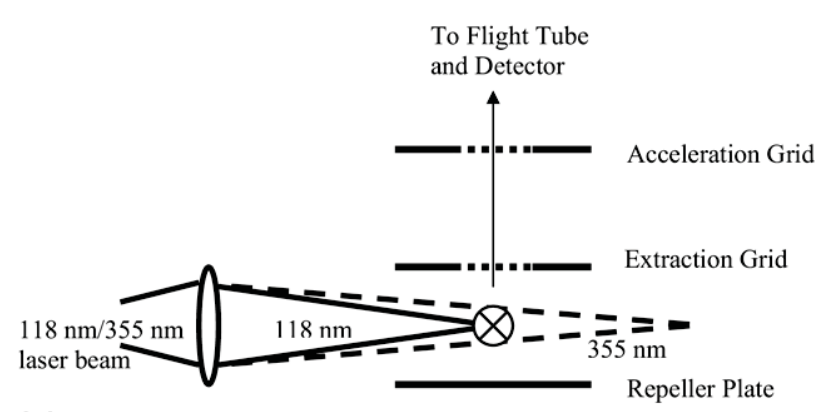

(a)

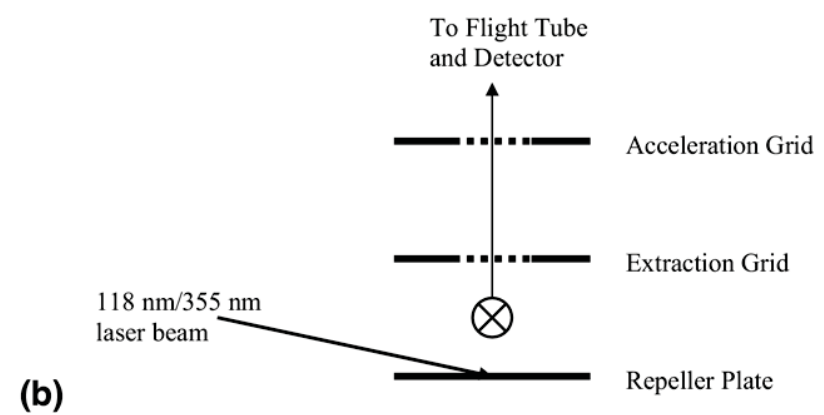

Figure 1. Schematic diagrams of the ionization sources in the ion optics regions of the TOF mass spectrometer for (a) single photon ionization, SPI, by $118 \mathrm{~nm}$ VUV photons, and (b) laser-induced electron impact ionization, LIEI, by hitting the repeller plate with the $118 \mathrm{~nm} / 355 \mathrm{~nm}$ laser beams. 
center of the space between the repeller and extraction grid. The $355 \mathrm{~nm}$ UV beam was focused beyond this point. The path of the laser beam was carefully adjusted such that it did not illuminate any metal surfaces in the ion optics.

In LIEI mode, the LiF lens was removed and the path of the laser was adjusted such that the laser beam hit the repeller plate at a shallow angle. Removal of the lens reduced, but did not eliminate, the $118 \mathrm{~nm}$ radiation intensity in the ionization region; at the same time it increased the beam divergence. Electrons created directly at the repeller plate should not, however, penetrate very far into the ionization region since they are attracted to the repeller plate which is held at $2.997 \mathrm{kV}$ compared with $2.775 \mathrm{kV}$ to the extraction grid. With the unfocused VUV/UV laser beams, photoelectrons can be produced by straight/scattered/reflected laser light. Being accelerated by the electric field in the ion source, these electrons subsequently gain sufficient energies to ionize the chemical species from the molecular beam exiting the reactor.

Ions produced by either SPI or LIEI were mass dispersed in a $1 \mathrm{~m}$-long linear TOF mass spectrometer and detected by a microchannel plate (MCP) detector at the end of the flight tube. Signals from the MCP detector were preamplified and displayed on an oscilloscope (Tektronics, TDS 3032B, Markham, Canada). The signals were averaged over 512 laser pulses before being saved to a computer. Pure $\mathrm{NH}_{3}(99.999 \%$, BOC gases), $1 \% \mathrm{SiH}_{4}$ in helium (BOC gases), and ultra high purity helium $(99.995 \%$, Praxair) were used to prepare the $\mathrm{SiH}_{4} / \mathrm{NH}_{3} / \mathrm{He}$ mixtures in a $2.25 \mathrm{~L}$ sample cylinder.

\section{Results and Discussions}

Source gaseous mixtures, including $50 \% \mathrm{NH}_{3}$ in helium (He), $1 \% \mathrm{SiH}_{4}$ in $\mathrm{He}$, and $\mathrm{NH}_{3} / \mathrm{SiH}_{4}$ mixtures in $\mathrm{He}$ with different pressure ratios of $\mathrm{NH}_{3}$ to $\mathrm{SiH}_{4}$, were studied in this work. The mass spectra from $\mathrm{NH}_{3}$ and $\mathrm{SiH}_{4}$ gases before and after the filament was turned on using both SPI and LIEI methods were recorded to evaluate the effectiveness of our LIEI source.

\section{$\mathrm{NH}_{3}$ and $\mathrm{SiH}_{4}$ Components}

The room-temperature mass spectra of $50 \% \mathrm{NH}_{3} / \mathrm{He}$ recorded under SPI and LIEI conditions are shown in Figure $2 a$ and $b$, respectively. The mass spectrum recorded using SPI is dominated by the parent mass at $m / z=17$. All other peaks including the $\mathrm{He}^{+}, \mathrm{NH}_{2}{ }^{+}$, and $\mathrm{NH}^{+}$are very weak. These weak peaks are attributed to electron impact (EI) ionization due to a small amount of photoelectrons caused by scattered UV radiation in the photoionization region. By changing to the LIEI method, the $\mathrm{He}^{+}, \mathrm{NH}_{2}{ }^{+}$, and $\mathrm{NH}^{+}$peaks are greatly enhanced, as expected. One more fragment peak of $\mathrm{N}^{+}$ was also observed. The IP of $\mathrm{He}$ is $24.6 \mathrm{eV}$. The appearance potentials (AP) of $\mathrm{NH}_{2}{ }^{+}, \mathrm{NH}^{+}$, and $\mathrm{N}^{+}$ from $\mathrm{NH}_{3}$ are $15.76 \mathrm{eV}, 17.1 \mathrm{eV}$, and $22.6 \mathrm{eV}$, respec-
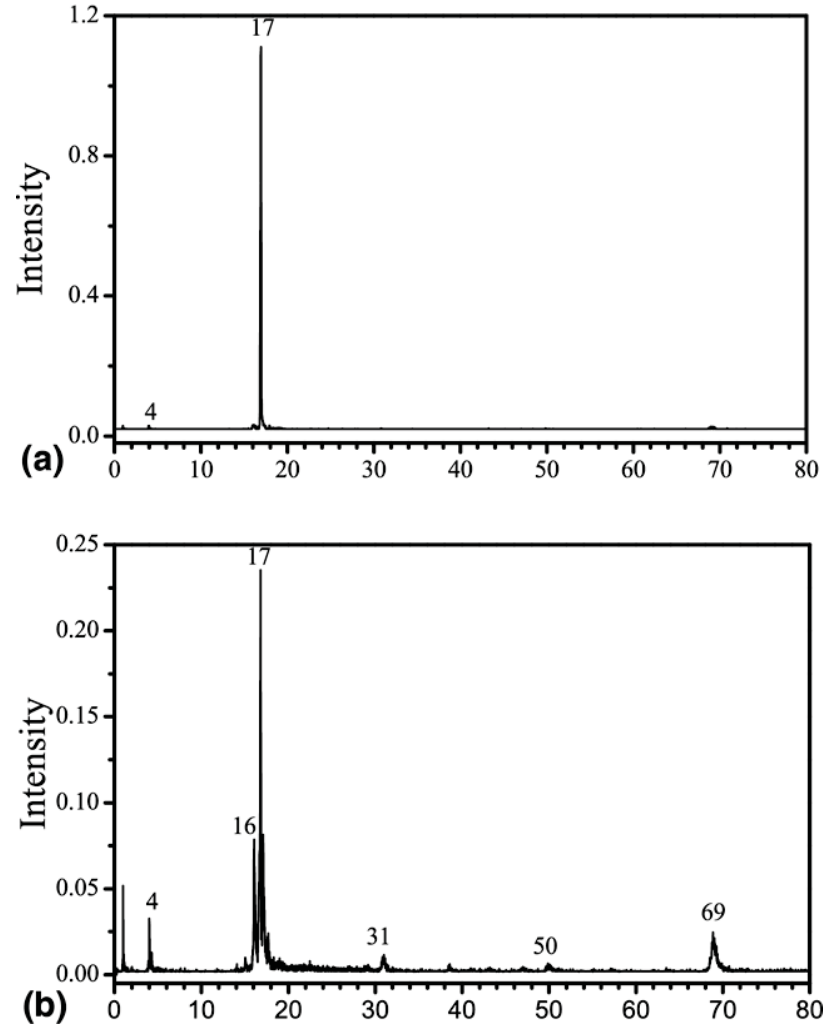

Figure 2. Room temperature mass spectra of $50 \% \quad \mathrm{NH}_{3} / \mathrm{He}$ recorded using (a) SPI mode; and (b) LIEI mode.

tively. All this indicates that EI source becomes important in the LIEI mode where the LiF lens is pulled out of the optical path and the laser beam is guided toward the repeller plate. Also of interest is the fact that the baseline is much less noisy when the SPI setup is used, a fact that has been observed by others [27]. When the LIEI source is used, the baseline is much noisier and background peaks at $m / z=1,31,50$, and 69 appear with increased intensity. It is also noted from Figure 2 that by changing from the SPI to LIEI source, the intensity of the $\mathrm{NH}_{3}$ peak is significantly reduced. The reason will be discussed later.

Figure 3 shows the comparison of the TOF mass spectra recorded for 12 torr of $50 \% \mathrm{NH}_{3} / \mathrm{He}$ mixture in the HWCVD reactor after the filament was turned on for $2 \mathrm{~min}$ at $1500{ }^{\circ} \mathrm{C}$ under SPI and LIEI conditions. Compared with the room-temperature mass spectra of the same mixture, clearly, after the filament was turned on, the intensity of $\mathrm{NH}_{3}$ peak decreases, while at the same time two new peaks at $m / z=2$ and 28 increase in intensity. These two new peaks correspond to $\mathrm{H}_{2}$ and $\mathrm{N}_{2}$ molecules, respectively, which are produced from hot-wire decomposition of $\mathrm{NH}_{3}$ in the reactor. In the work by Umemoto et al. [12], it was found that the primary decomposition products of $\mathrm{NH}_{3}$ on the $\mathrm{W}$ filament are $\mathrm{NH}_{2}$ and $\mathrm{H}$ radicals. They also detected the stable $\mathrm{N}_{2}$ and $\mathrm{H}_{2}$ molecules using mass spectrometer. Melton and Emmett [28] show that the N-containing species in the catalytic decomposition of $\mathrm{NH}_{3}$ over $\mathrm{Pt}$ at 

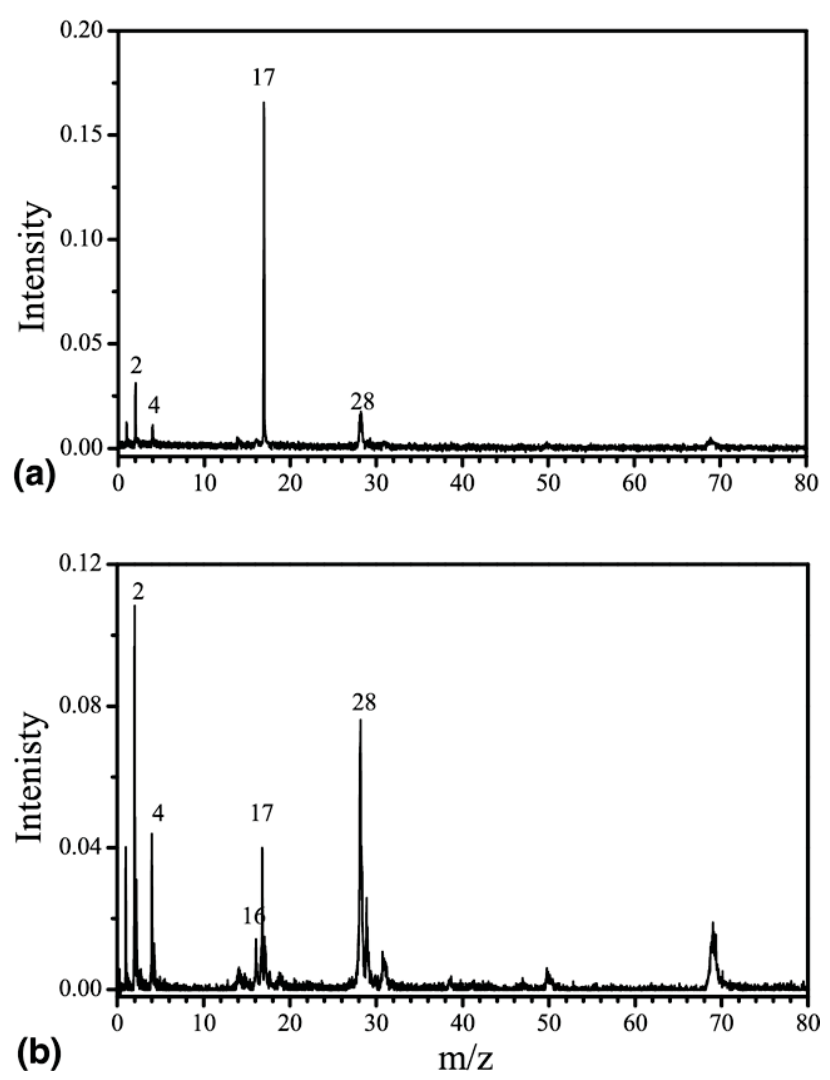

Figure 3. Mass spectra of $50 \% \mathrm{NH}_{3} / \mathrm{He}$ sample after the $\mathrm{W}$ filament was turned on for $2 \mathrm{~min}$ at $1500{ }^{\circ} \mathrm{C}$ recorded with (a) SPI mode; and (b) LIEI mode.

a pressure of 0.1 torr and a temperature of $1200{ }^{\circ} \mathrm{C}$ are $\mathrm{N}_{2}, \mathrm{NH}_{2}, \mathrm{NH}$, and $\mathrm{N}$, with $\mathrm{N}_{2}$ as the dominant of all. $\mathrm{NH}_{2}$ is the most abundant radical species detected among the three. One of the important $\mathrm{NH}_{2}$ loss channel proposed by Stohard et al. [29] is the heterogeneous reactions on the chamber wall, which is found to be much faster than the gas-phase biradical combination reactions. In our experiment, the dominant species when the $\mathrm{W}$ filament is on are the stable $\mathrm{H}_{2}$ and $\mathrm{N}_{2}$ molecules. They are believed to be formed by reactions on the chamber walls [26].

The impact of the LIEI source on the observed mass spectra is dramatic as seen from comparing Figure 3a and $b$. In using LIEI, the intensities of the two product peaks, i.e., $\mathrm{H}_{2}$ and $\mathrm{N}_{2}$, are significantly enhanced. This is clearly more representative of the product distributions in the reactor with $\mathrm{NH}_{3}$ gas in. The mass resolution $(\mathrm{m} / \Delta \mathrm{m})$ of the $\mathrm{H}_{2}, \mathrm{~N}_{2}$, and He peaks observed with LIEI source is found to be not higher than 115, which is much less than the mass resolution for the $\mathrm{NH}_{3}$ peak recorded using SPI method, typically of 200. This implies that the enhanced signals of $\mathrm{H}_{2}, \mathrm{~N}_{2}$, and $\mathrm{He}$ come from the electron impact ionization source. As mentioned before, the $\mathrm{NH}_{2}{ }^{+}(m / z=16)$ and $\mathrm{NH}^{+}(m / z=15)$ peaks were observed in the room-temperature mass spectra of $\mathrm{NH}_{3}$. The intensities of these two peaks decreased with their parent ion, $\mathrm{NH}_{3}{ }^{+}$, after the fila- ment was turned on. Examination of the intensity ratios of $\mathrm{NH}_{2}{ }^{+} / \mathrm{NH}_{3}{ }^{+}$and $\mathrm{NH}^{+} / \mathrm{NH}_{3}{ }^{+}$from the entire filament on mass spectra of $\mathrm{NH}_{3}$ shows no obvious increase. Therefore, the $\mathrm{NH}_{2}{ }^{+}$and $\mathrm{NH}^{+}$signals should originate from the dissociation of $\mathrm{NH}_{3}$ upon ionization, and they are not related to dissociation of $\mathrm{NH}_{3}$ on the hot $\mathrm{W}$ filament. This is not surprising since the $\mathrm{NH}_{2}$ and $\mathrm{NH}$ radicals produced directly from the hot filament cannot survive the sampling conditions in our HWCVD reactor. However, the intensity of the peak at $\mathrm{m} / \mathrm{z}=14$ is seen to increase after the filament is on. The peak is most likely the $\mathrm{N}^{+}$signal from the dissociation of $\mathrm{N}_{2}{ }^{+}$ upon ionization. This is supported by the fact that the time distribution curves of two peaks at $\mathrm{m} / \mathrm{z}=28$ and 14 are very similar.

At a filament temperature of $1500{ }^{\circ} \mathrm{C}$, the $\mathrm{NH}_{3}$ peak intensity reached a steady-state after about $3 \mathrm{~min}$. The intensities of the two products, $\mathrm{N}_{2}$ and $\mathrm{H}_{2}$, also reached their respective steady-state at the same time. With increasing filament temperatures, the time to reach the steady-state intensities is shortened. At $\mathrm{T} \geq 1800{ }^{\circ} \mathrm{C}$, the steady-state intensity is achieved right after the filament is on. At the steady state, the intensity ratio of the three peaks is found to be 0.0207:0.715:1.00 for $\mathrm{NH}_{3}: \mathrm{N}_{2}: \mathrm{H}_{2}$. By using the reference mass spectra of a mixture sample with $\mathrm{H}_{2}, \mathrm{~N}_{2}$, and $\mathrm{NH}_{3}$ in equal quantities recorded under the same LIEI conditions, the true ratio of the three molecules in the HWCVD reactor can be determined to be $0.0130: 0.291: 1.00$. This suggests that at the steady-state in the HWCVD reactor, the amount of $\mathrm{H}_{2}$ is the greatest among the three stable molecules, the $\mathrm{N}_{2}$ steady-state intensity is $29.1 \%$ that of $\mathrm{H}_{2}$, and $\mathrm{NH}_{3}$ is only $1.30 \%$ that of $\mathrm{H}_{2}$. The average decomposition percentage of $\mathrm{NH}_{3}$ when using the $50 \% \mathrm{NH}_{3} / \mathrm{He}$ sample is found to be $98.8 \%$, close to a complete decomposition.

For the $\mathrm{SiH}_{4}$ component, the principal gas-phase reaction products were found to be $\mathrm{H}_{2}, \mathrm{Si}_{2} \mathrm{H}_{6}(m / z=62)$, and $\mathrm{Si}_{3} \mathrm{H}_{8}(\mathrm{~m} / \mathrm{z}=92)$ from our experiments with 12 torr of $1 \% \mathrm{SiH}_{4} / \mathrm{He}$ mixture. This is shown in Figure 4, the mass spectra of $1 \% \mathrm{SiH}_{4}$ recorded right after the filament was turned on at $1500{ }^{\circ} \mathrm{C}$. The two peaks observed at $\mathrm{m} / \mathrm{z}=60$ and 90 are believed to be formed from photoionization of $\mathrm{Si}_{3} \mathrm{H}_{8}$ and $\mathrm{Si}_{4} \mathrm{H}_{10}$, respectively, formed in the reactor [9]. All other mass peaks except that at $m / z=4\left(\mathrm{He}^{+}\right)$are from background. The broad peak at an $\mathrm{m} / \mathrm{z}$ value of around 40 is found to be due to the filament on process. The reason for the observation of this broad feature is currently unclear. It can be seen from Figure 4 that the intensities of the $\mathrm{Si}_{2} \mathrm{H}_{6}{ }^{+}$(IP $=9.7$ $\mathrm{eV})$ and $\mathrm{Si}_{3} \mathrm{H}_{8}{ }^{+}(\mathrm{IP}=9.2 \mathrm{eV})$ are enhanced when the SPI method was used. Similar to what was observed for $50 \% \mathrm{NH}_{3}$, the $\mathrm{H}_{2}{ }^{+}$and $\mathrm{He}^{+}$peaks were stronger when using the LIEI method. It is noted that a weak photofragment peak of $\mathrm{SiH}_{2}{ }^{+}(\mathrm{m} / \mathrm{z}=30)$ from $\mathrm{SiH}_{4}(\mathrm{AP}=11.6$ $\mathrm{eV)}$ were observed using either SPI or LIEI, and its intensity was found to be enhanced when using LIEI mode. After the filament was turned on, the $\mathrm{SiH}_{2}{ }^{+}$peak intensity decayed rapidly with filament on time for each temperature tested. The same intensity was also 

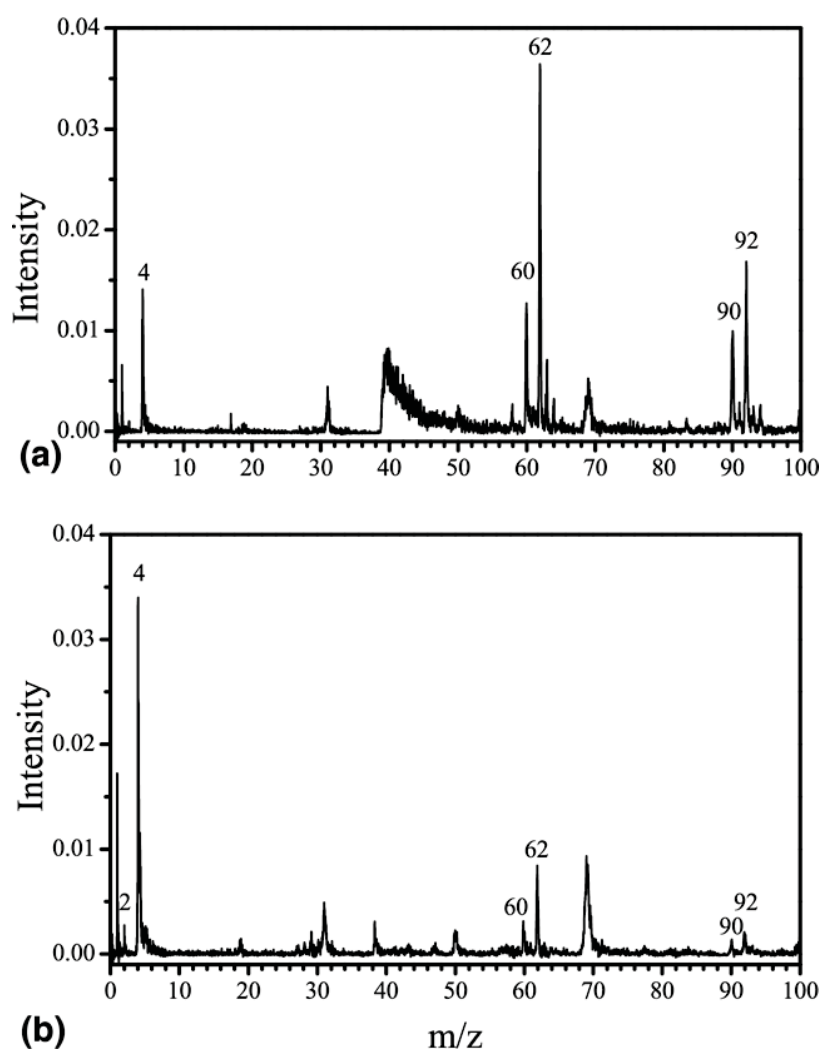

Figure 4. Mass spectra of $1 \% \mathrm{SiH}_{4} / \mathrm{He}$ sample right after the $\mathrm{W}$ filament was turned on $(\mathrm{t}=0 \mathrm{~min})$ at $1500{ }^{\circ} \mathrm{C}$ recorded with (a) SPI mode; and (b) LIEI mode.

found to decrease with increasing filament temperatures. Therefore, the enhanced $\mathrm{SiH}_{2}{ }^{+}(\mathrm{m} / \mathrm{z}=30)$ signal observed with LIEI source provides good indication of the $\mathrm{SiH}_{4}$ depletion in the reactor since its parent ion is difficult to observe.
In SPI mode, the $118 \mathrm{~nm}$ photons are focused directly into the molecular beam, and so the intensity of $10.5 \mathrm{eV}$ radiation is high. Under these conditions, it would be expected that any peak corresponding to a species that can be ionized by the $118 \mathrm{~nm}$ photons (IP $<10.5 \mathrm{eV}$ ) would increase in intensity. The corollary of this is that any species that cannot be ionized by $10.5 \mathrm{eV}$ radiation would experience a decrease in peak intensity. Examination of the behavior of the $\mathrm{SiH}_{4}-\mathrm{NH}_{3}$ samples demonstrates that this is indeed the case. The best illustration of the effect can be made using the $\mathrm{NH}_{3}, \mathrm{Si}_{2} \mathrm{H}_{6}, \mathrm{H}_{2}$, and $\mathrm{N}_{2}$ peaks. Both $\mathrm{NH}_{3}$ and $\mathrm{Si}_{2} \mathrm{H}_{6}$ have IPs below 10.5 $\mathrm{eV}$, and both show a greater intensity in SPI mode compared with LIEI mode. $\mathrm{H}_{2}$ and $\mathrm{N}_{2}$, by contrast, are significantly weaker when SPI mode is employed. Evidently any species capable of being ionized by $10.5 \mathrm{eV}$ radiation has a higher intensity in SPI mode, whereas species with IP $>10.5 \mathrm{eV}$ are only effectively ionized when LIEI is used.

\section{$\mathrm{SiH}_{4} / \mathrm{NH}_{3}$ Mixtures}

The experiments on the two pure components, i.e., $\mathrm{SiH}_{4}$ and $\mathrm{NH}_{3}$, have shown that the LIEI source coupled with TOF MS provides a useful tool to diagnose the gasphase chemical species involved with both $\mathrm{SiH}_{4}$ and $\mathrm{NH}_{3}$ in the HWCVD reactor. Therefore, it is the method of choice to study the behavior of $\mathrm{SiH}_{4} / \mathrm{NH}_{3}$ mixture in the same reactor. Figure 5 shows the mass spectra recorded for the 1:1 $\mathrm{NH}_{3}: \mathrm{SiH}_{4}$ mixture after the filament was turned on at $1500{ }^{\circ} \mathrm{C}$ for 0,2 , and $5 \mathrm{~min}$, respectively. The room-temperature spectrum of the same mixture is shown for comparison. The peaks representative of the $\mathrm{SiH}_{4}$ chemistry in the reactor, i.e., the $\mathrm{Si}_{2} \mathrm{H}_{6}$ $(m / z=62), \mathrm{Si}_{3} \mathrm{H}_{8}(m / z=92)$, and $\mathrm{H}_{2}$, were observed from the mass spectra. Similar to $1 \% \mathrm{SiH}_{4} / \mathrm{He}$ sample,
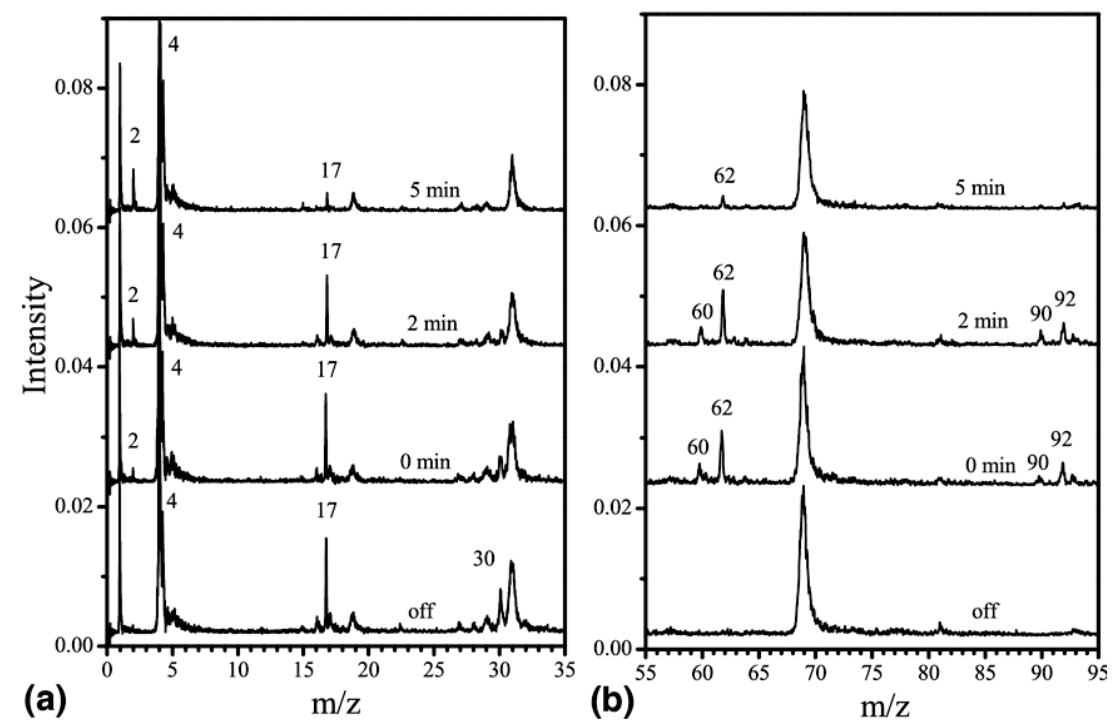

Figure 5. The LIEI mass spectra of the $\mathrm{NH}_{3} / \mathrm{SiH}_{4}$ mixture $\left[\mathrm{P}\left(\mathrm{NH}_{3}\right): \mathrm{P}\left(\mathrm{SiH}_{4}\right)=1: 1\right]$ recorded 0 , 2, and 5 min after the filament was on at $1500{ }^{\circ} \mathrm{C}$ in mass regions (a) between 0 and $35 \mathrm{amu}$; and (b) between 55 and $95 \mathrm{u}$. 
the peaks at $m / z=62$ and 92 decay with increasing filament-on time, whereas the $\mathrm{H}_{2}$ peak increases to a steady-state intensity. On the other hand, the characteristic product peak of $\mathrm{N}_{2}$ from $\mathrm{NH}_{3}$ chemistry was not observed for this mixture even after the filament was turned on at $1500{ }^{\circ} \mathrm{C}$ for $5 \mathrm{~min}$. At this temperature, for the pure $\mathrm{NH}_{3}$ component, the $\mathrm{N}_{2}$ steady-state intensity was achieved $3 \mathrm{~min}$ after the filament was turned on. Therefore, it can be concluded that when equal quantity of $\mathrm{SiH}_{4}$ and $\mathrm{NH}_{3}$ is mixed, $\mathrm{SiH}_{4}$ chemistry is dominant and the $\mathrm{NH}_{3}$ chemistry is suppressed by the addition of $\mathrm{SiH}_{4}$. At a raised filament temperature of $1800^{\circ} \mathrm{C}$, signals from $\mathrm{N}_{2}$ peak start to come out, indicating a lesser extent of suppression at higher temperatures. Although the $\mathrm{N}_{2}$ peak was not observed at $\mathrm{T}<1800^{\circ} \mathrm{C}$, the $\mathrm{NH}_{3}$ peak intensity was found to decrease. For example, right after the filament was turned on at $1500{ }^{\circ} \mathrm{C}$ and $1800{ }^{\circ} \mathrm{C}$, the $\mathrm{NH}_{3}$ peak intensity is decreased by $81.2 \%$ and $87.5 \%$, respectively. It is known that gas-phase reactions, such as $\mathrm{H}+\mathrm{NH}_{3}$ and $\mathrm{SiH}_{4}+$ $\mathrm{NH}_{3}$, are slow [30, 31]; therefore, the consumption of $\mathrm{NH}_{3}$ in the secondary gas-phase reactions is less likely. The decrease in the $\mathrm{NH}_{3}$ signal is probably due to surface reactions.

Various other $\mathrm{SiH}_{4} / \mathrm{NH}_{3}$ mixtures with increasing $\mathrm{NH}_{3}$ contents were studied in this work. The compositions of these mixtures are listed in Table 1. At the lowest filament temperature of $1500{ }^{\circ} \mathrm{C}$ tested, no mixtures show a decrease in the $\mathrm{NH}_{3}$ peak intensity for the full 10-min run except that the 200:1 $\mathrm{NH}_{3}: \mathrm{SiH}_{4}$ mixture shows an $11.3 \%$ decrease at a filament-on time of $10 \mathrm{~min}$ compared with its room-temperature intensity. With increasing filament temperature and filament-on time, the $\mathrm{NH}_{3}$ peak intensity starts to decrease. Table 2 lists the $\mathrm{NH}_{3}$ decomposition percentage for the 200:1, 100:1, 50:1, and 20:1 $\mathrm{NH}_{3} / \mathrm{SiH}_{4}$ mixtures 0 , 5, and $10 \mathrm{~min}$, respectively, after the filament is on at $1500{ }^{\circ} \mathrm{C}, 1700{ }^{\circ} \mathrm{C}$, and $2000{ }^{\circ} \mathrm{C}$. The experimental error for the $\mathrm{NH}_{3}$ decomposition percentages was determined to be no greater than 4.9 from the measurements of $50 \%$ $\mathrm{NH}_{3} / \mathrm{He}$ sample. Comparison of the $50 \% \mathrm{NH}_{3} / \mathrm{He}$ and 100:1 $\mathrm{NH}_{3} / \mathrm{SiH}_{4} / \mathrm{He}$ samples clearly shows the negative effect of $\mathrm{SiH}_{4}$ addition on the decomposition of $\mathrm{NH}_{3}$. Only at a filament temperature of $2000{ }^{\circ} \mathrm{C}$ do the two samples show comparable behavior regarding the $\mathrm{NH}_{3}$ decomposition. By comparing the 200:1, 50:1, and

Table 1. The composition of various $\mathrm{SiH}_{4} / \mathrm{NH}_{3}$ mixtures and the filament-on time to reach the $\mathrm{N}_{2}$ steady-state intensity

\begin{tabular}{lrrrrc}
\hline & & & \multicolumn{3}{c}{ Time (min) } \\
\cline { 4 - 6 } Mixtures & $\begin{array}{r}\mathrm{P}_{\left(\mathrm{NH}_{3}\right)^{\mathrm{a}}} \\
\text { (torr) }\end{array}$ & $\begin{array}{c}\mathrm{P}\left(\mathrm{SiH}_{4}\right) \\
\text { (torr) }\end{array}$ & $1800{ }^{\circ} \mathrm{C}$ & $1900{ }^{\circ} \mathrm{C}$ & $2000{ }^{\circ} \mathrm{C}$ \\
\hline \hline $50 \% \mathrm{NH}_{3}$ & 1000 & 0 & 0 & 0 & 0 \\
$200: 1$ & 660 & 3.3 & 3 & 2 & 1 \\
$100: 1$ & 1000 & 10 & 3 & 3 & 2 \\
$50: 1$ & 660 & 13.5 & 3 & 3 & 2 \\
$20: 1$ & 380 & 16.3 & 5 & 3 & 2 \\
\hline
\end{tabular}

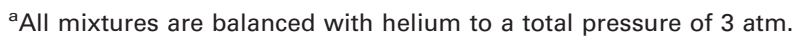

Table 2. The decomposition percentage of $\mathrm{NH}_{3}$ for the four $\mathrm{NH}_{3} / \mathrm{SiH}_{4}$ mixtures and $50 \% \mathrm{NH}_{3} / \mathrm{He}$

\begin{tabular}{lccccc}
\hline & $50 \% \mathrm{NH}_{3}$ & $200: 1$ & $100: 1$ & $50: 1$ & $20: 1$ \\
\hline \hline $1500{ }^{\circ} \mathrm{C}$ at $0 \mathrm{~min}$ & 37.1 & 0 & 0 & 0 & 0 \\
$1500{ }^{\circ} \mathrm{C}$ at $5 \mathrm{~min}$ & 98.0 & 0 & 0 & 0 & 0 \\
$1500{ }^{\circ} \mathrm{C}$ at $10 \mathrm{~min}$ & 99.4 & 11.0 & 0 & 0 & 0 \\
$1700{ }^{\circ} \mathrm{C}$ at $0 \mathrm{~min}$ & 79.4 & 0 & 0 & 0 & 0 \\
$1700{ }^{\circ} \mathrm{C}$ at $5 \mathrm{~min}$ & 98.6 & 76.1 & 29.2 & 32.2 & 0 \\
$1700{ }^{\circ} \mathrm{C}$ at $10 \mathrm{~min}$ & 99.2 & 96.1 & 54.7 & 62.1 & 4.9 \\
$2000{ }^{\circ} \mathrm{C}$ at $0 \mathrm{~min}$ & 92.8 & 62.0 & 29.2 & 57.4 & 19.4 \\
$2000{ }^{\circ} \mathrm{C}$ at $5 \mathrm{~min}$ & 99.1 & 98.6 & 99.0 & 98.9 & 98.9 \\
$2000{ }^{\circ} \mathrm{C}$ at $10 \mathrm{~min}$ & 99.2 & 99.0 & 99.1 & 99.0 & 99.4 \\
\hline
\end{tabular}

20:1 $\mathrm{NH}_{3} / \mathrm{SiH}_{4} / \mathrm{He}$ samples, it can be seen that the suppression of $\mathrm{SiH}_{4}$ on the $\mathrm{NH}_{3}$ decomposition is enhanced with the increasing amount of $\mathrm{SiH}_{4}$ in the mixture.

For all the mixtures listed in Table 1, when the $\mathrm{NH}_{3}$ peak shows a decrease in intensity, the $\mathrm{N}_{2}$ peak is observed in the mass spectra. Below filament temperatures of $1700^{\circ} \mathrm{C}$, if observed, the intensity of the $\mathrm{N}_{2}$ peak from all the mixture keeps increasing with filament-on time. No steady-state intensity is reached at the end of the 10-min run for each tested temperature lower than $1700{ }^{\circ} \mathrm{C}$. This is in sharp contrast with the behavior of the pure $\mathrm{NH}_{3}$ component. At temperatures higher than $1800{ }^{\circ} \mathrm{C}$, the $\mathrm{N}_{2}$ intensity reaches a steadystate for all mixtures. However, the time it takes to reach the steady-state intensity is different, as shown in Table 1. With more $\mathrm{SiH}_{4}$ in the mixture, the time taken to achieve the $\mathrm{N}_{2}$ steady-state intensity is increased. This supports the conclusion that more $\mathrm{SiH}_{4}$ molecules suppress the $\mathrm{NH}_{3}$ decomposition to an even greater extent.

Previous study on the deposition chemistry of $\mathrm{SiH}_{4} /$ $\mathrm{NH}_{3}$ mixtures in HWCVD [14] also showed the negative effect of $\mathrm{SiH}_{4}$ addition on the $\mathrm{NH}_{3}$ decomposition. The reason was ascribed to the competition of active catalytic sites on the filament between $\mathrm{SiH}_{4}$ and $\mathrm{NH}_{3}$. In our experiments with the $\mathrm{SiH}_{4} / \mathrm{NH}_{3}$ mixtures, consistent observation was made that an increased current was needed to maintain a constant filament temperature. At certain point, a temperature jump occurred, accompanied by the rapid decrease of the $\mathrm{NH}_{3}$ peak intensity and strong build-up of the $\mathrm{N}_{2}$ and $\mathrm{H}_{2}$ peak intensities in the mass spectra. This suggests that $\mathrm{SiH}_{4}$ interacts with the filament more aggressively than $\mathrm{NH}_{3}$, forming silicide on the filament, and this is why more power is needed to maintain the filament temperature. The presence of silicon element on the surface of $\mathrm{W}$ filament exposed to the $\mathrm{SiH}_{4} / \mathrm{NH}_{3}$ mixtures is confirmed using the electron microprobe analysis (EMPA) (JEOL JXA-8200) of filament. When $\mathrm{NH}_{3}$ takes over the filament at a later time and with the power build-up on the filament, the electrical properties and the emissivity of the filament changed, causing a temperature spike. The access of $\mathrm{NH}_{3}$ to the filament decomposes the molecule and the corresponding stable 
products, $\mathrm{H}_{2}$ and $\mathrm{N}_{2}$, are then detected by our mass spectrometer. Therefore, our experimental observations also suggest that when $\mathrm{SiH}_{4}$ and $\mathrm{NH}_{3}$ are mixed in the HWCVD reactor, they tend to compete for the active site on the filament. $\mathrm{SiH}_{4}$ is clearly more dominant in this regard.

\section{The Ionization Process}

The capability of the LIEI source for detecting the gas-phase chemical products formed in the HWCVD processes with $\mathrm{SiH}_{4}, \mathrm{NH}_{3}$ and their mixtures has been clearly demonstrated by the experimental results presented above. Effort is also made in our study to understand the nature of the ionization process. In the LIEI mode, the $355 \mathrm{~nm}$ UV beam passes the frequencytripling gas cell filled with $\mathrm{Ar} / \mathrm{Xe}$ before it hits the repeller plate. The two wavelengths, $355 \mathrm{~nm}$ and 118 $\mathrm{nm}$, are not separated before the beam's arrival in the ionization chamber. Although the $118 \mathrm{~nm}$ VUV photons have much higher energy than the $355 \mathrm{~nm}$ UV photons, the intensity of VUV light is much lower due to the low conversion efficiency of about $10^{-5}$ [32]. In our experiments, it was found that signals from $\mathrm{Na}^{+}$and $\mathrm{K}^{+}$were observed in a few instances or when the $355 \mathrm{~nm}$ UV light intensity was increased; however, other metal ion peaks such as the iron ion peak were absent. These alkali metals have work functions below $3.5 \mathrm{eV}$, whereas the work functions of the main components in stainless steel, e.g., iron and nickel, are above $3.5 \mathrm{eV}$. This suggests that the $355 \mathrm{~nm}$ radiation is a much more likely candidate responsible for photoelectron emission in the LIEI mode. It is noted from Figure 2a and Figure 3a that in the SPI mode, where care was taken to prevent the laser light from hitting any surfaces, signals originating from LIEI, e.g., $\mathrm{H}_{2}{ }^{+}, \mathrm{He}^{+}$, and $\mathrm{N}_{2}{ }^{+}$, are still observable, but at reduced intensities. In this mode, when the tripling medium, Xe gas, was pumped out of the gas cell, the $\mathrm{NH}_{3}$ peak in Figure 2a and Figure 3a is completely gone, as expected. However, the intensities of the $\mathrm{H}_{2}{ }^{+}, \mathrm{He}^{+}$, and $\mathrm{N}_{2}{ }^{+}$peaks were found to stay the same as those with the Xe gas in the cell. This clearly demonstrates that the weak LIEI signals present in the mass spectra recorded using the SPI mode is caused by scattered $355 \mathrm{~nm}$ UV light in the ionization region. Therefore, it is believed that the $355 \mathrm{~nm}$ UV beam is responsible for producing pulsed electrons beam in both ionization methods.

In the LIEI mode, although the $355 \mathrm{~nm}$ UV laser beam was directed to the repeller plate held at much higher positive potential than the extraction grid in the TOF MS, the results presented above have shown that the LIEI source works well. Previous work by Schriemer and $\mathrm{Li}$ [22] has also illustrated that ion signals were observed by striking the repeller plate with a laser beam. It is unlikely that the repeller would be the main source of ionizing electrons. The small kinetic energy the electrons obtain in the laser-induced photoelectron emission process is not enough to even drive them 0.1 $\mathrm{mm}$ into the ionization region and it is impossible for them to be accelerated to energies above $10.5 \mathrm{eV}$. More probable is that the electrons originate from straight/ reflected/scattered laser light hitting the extraction grid and/or other metal surfaces as seen by Colby and Reilly [20]. Such electrons can then be accelerated to hundreds of $\mathrm{eV}$ by the extraction field between the repeller plate and extraction grid. Under the LIEI mode used in our experiment, the LiF lens was pulled out of the optical path, therefore, the laser light is divergent. A measurement of the UV beam divergence under the condition of LIEI mode indicates a beam spot size with a diameter of about $15 \mathrm{~mm}$, which is larger than the spacing of 12.7 $\mathrm{mm}$ between the repeller and the extraction plates. Therefore, the divergent UV beam can hit the extraction plate to produce photoelectrons that can be used for molecular ionization. In our current experimental setup, it is not likely to guide the $355 \mathrm{~nm}$ UV beam toward the extraction plate directly and still be able to generate the $118 \mathrm{~nm}$ VUV laser radiation. A more controlled generation of photoelectrons will be necessary before a more complete understanding of the ionization process can be obtained. Such experiments are currently underway.

Comparison between the SPI and the LIEI source indicates that SPI tends to give mass peaks with a good resolution while the peaks from the LIEI source are broader. This is probably due to the broad initial spatial distribution of the ions generated in the LIEI source, as has been discussed in previous work [23, 25]. In the LIEI mode used in our experiment, two laser beams with different wavelengths are present in the ionization region; therefore, the species with IPs below $10.5 \mathrm{eV}$ can be ionized simultaneously by SPI and LIEI sources. For the $\mathrm{NH}_{3}$ peak (IP: $10.07 \mathrm{eV}$ ), it is interesting to note that the peaks due to SPI and LIEI for the same mass were somewhat separated in time as can be seen in Figure 6. The $\mathrm{NH}_{3}$ ions due to LIEI $(\mathrm{t}=6.104 \mu \mathrm{s})$ arrive at the detector a bit later than those due to SPI $(t=6.054 \mu \mathrm{s})$. The peak at $\mathrm{t}=5.918 \mu \mathrm{s}$ is from $\mathrm{NH}_{2}{ }^{+}$and the source for the peak at $\mathrm{t}=6.208 \mu \mathrm{s}$ is unknown. The average intensity ratio of the $\mathrm{NH}_{2}{ }^{+}, \mathrm{NH}^{+}$peak, respectively, to the $\mathrm{NH}_{3}{ }^{+}$due to LIEI is found to be $0.89: 1$ and $0.088: 1$. This is comparable to the ratio of $0.81: 1$ and $0.076: 1$ for $\mathrm{NH}_{2}{ }^{+} / \mathrm{NH}_{3}{ }^{+}$and $\mathrm{NH}^{+} / \mathrm{NH}_{3}{ }^{+}$from the conventional $70 \mathrm{eV}$ EI MS of $\mathrm{NH}_{3}$, implying the electron energy in the LIEI source should be close to $70 \mathrm{eV}$. Considering the electric field of $175 \mathrm{~V} / \mathrm{cm}$ between the repeller plate and the extraction grid, the ionization would occur in a spatial region closer to the extraction plate, consistent with the origin of the photoelectrons being from the extraction plate. This may also explain why the $\mathrm{NH}_{3}$ ions due to the energetic electrons arrive at a later time than the same ions from VUV photoionization, which occurs at the center of the repeller plate and the extraction grid.

A characteristic feature of the current LIEI source is the presence of both $118 \mathrm{~nm} \mathrm{VUV}$ and $355 \mathrm{~nm} \mathrm{UV}$ radiations in the ionization region, leading to the coex- 


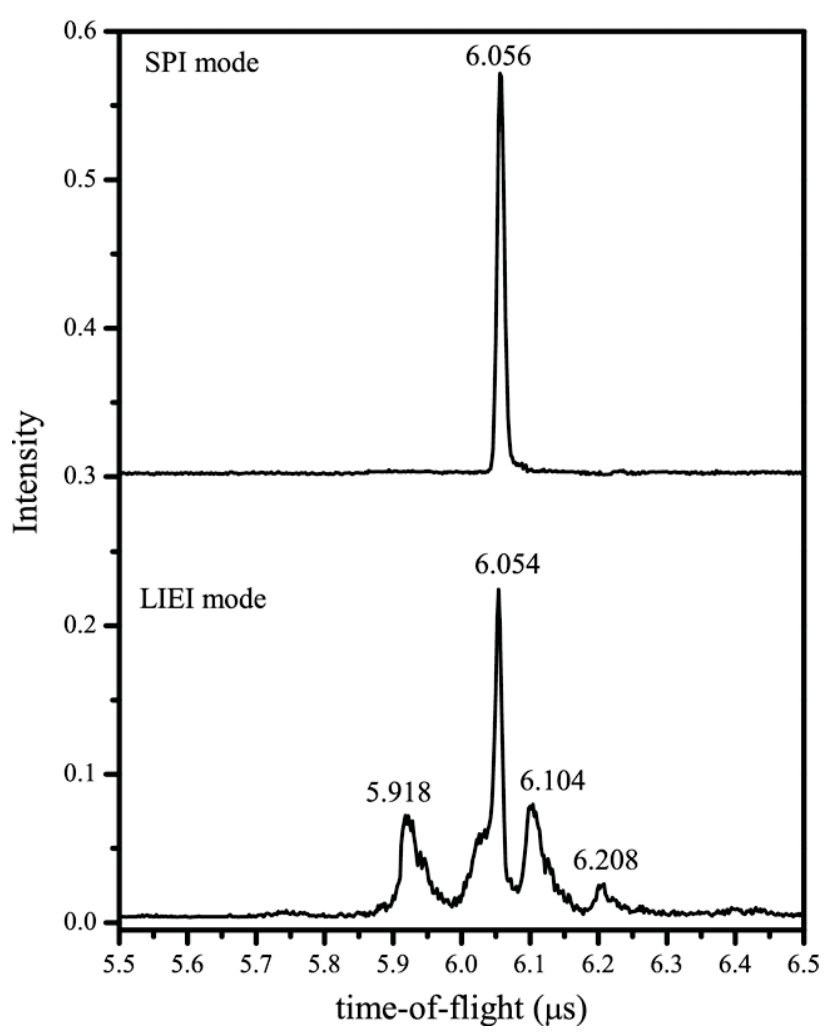

Figure 6. Room temperature mass spectra of the $\mathrm{NH}_{3} / \mathrm{SiH}_{4}$ mixture $\left[\mathrm{P}\left(\mathrm{NH}_{3}\right): \mathrm{P}\left(\mathrm{SiH}_{4}\right)=100: 1\right]$ in the time-of-flight region of $\mathrm{NH}_{3}$ recorded under SPI and LIEI modes.

istence of SPI and LIEI mode. A valuable consequence is that while it enables us to observe the species with IPs above $10.5 \mathrm{eV}$, the peaks with IPs below $10.5 \mathrm{eV}$ are visible with great intensity. As a result, the current LIEI source enables us to simultaneously observe all species of interest. As mentioned previously, SPI is a "soft" ionization method having a great advantage of generating molecular ions with relatively little fragmentation of the parent molecule. The EI source complements the SPI source in the sense that a "fingerprint" fragmentation pattern can be obtained for structure identification. An ionization source allowing the simultaneous observation of the molecular ion with great intensity (from SPI) and its fragment ions (from EI) would be advantageous, especially for monitoring reactions in which numerous species may appear at a given $m / z$ value. In this way, an even more "universal" technique than 118 $\mathrm{nm}$ SPI alone is developed, and it is possible to identify unknowns using reference electron impact spectra from databases and also its parent mass. For the $\mathrm{SiH}_{4}-\mathrm{NH}_{3}$ system, for example, the observation of $\mathrm{NH}^{+}, \mathrm{NH}_{2}{ }^{+}$ signals together with an enhanced $\mathrm{NH}_{3}{ }^{+}$parent ion provide additional information about the parent ion. The increased intensity in the peak at $\mathrm{m} / \mathrm{z}=14$ representing $\mathrm{N}^{+}$with the product peak at $\mathrm{m} / \mathrm{z}=28$ confirms the assignment of the peak to $\mathrm{N}_{2}$. It is anticipated that with increasing complexity of the source molecular system, the observation of both parent ions and its fragmentation peaks should provide significant help in positive identification of structure isomers produced in the complex HWCVD systems.

\section{Conclusions}

The gas-phase chemical species produced from a HWCVD reactor with $\mathrm{SiH}_{4}, \mathrm{NH}_{3}$, and their mixtures with different pressure ratios were examined using the conventional $118 \mathrm{~nm}$ VUV SPI source and a newlydeveloped LIEI source. Comparison of both ionization sources has shown that species with an IP below 10.5 $\mathrm{eV}$, such as $\mathrm{Si}_{2} \mathrm{H}_{6}, \mathrm{Si}_{3} \mathrm{H}_{8}$, and $\mathrm{NH}_{3}$, exhibited stronger peaks in the mass spectra recorded under SPI conditions. Species with IPs above $10.5 \mathrm{eV}$, such as $\mathrm{H}_{2}, \mathrm{~N}_{2}$ and $\mathrm{He}$, were only weakly visible under the same conditions. The incorporation of the LIEI source significantly enhanced the intensity of those species with IPs above $10.5 \mathrm{eV}$. Consequently, the mass spectra recorded with LIEI source is more representative of the product distributions for the source gas systems under study. A unique feature of the developed LIEI source is the coexistence of the SPI source due to the $118 \mathrm{~nm}$ VUV light. In using this ionization source, a simultaneous observation of parent ions with enhanced intensity from VUV SPI and their "fingerprint" fragmentation ions from LIEI has been achieved. This should provide a useful ionization source for distinguishing structure isomers often present in a complex HWCVD system. More importantly, this is achieved in one ionization source; no switch between SPI and LIEI modes via apparatus modification is needed.

The LIEI source developed proves to be very useful in studying the gas-phase chemistry in the process of HWCVD with the $\mathrm{SiH}_{4}-\mathrm{NH}_{3}$ system. Examination of a $\mathrm{SiH}_{4} / \mathrm{NH}_{3}$ mixture with a pressure ratio of $1: 1$ shows that $\mathrm{SiH}_{4}$ chemistry is predominant when equal quantity of $\mathrm{SiH}_{4}$ and $\mathrm{NH}_{3}$ is mixed. The $\mathrm{N}_{2}$ product characteristic of $\mathrm{NH}_{3}$ chemistry in the reactor is absent with this mixture at low temperatures, indicating a negative effect from the $\mathrm{SiH}_{4}$ addition on the $\mathrm{NH}_{3}$ chemistry. Study of various other $\mathrm{SiH}_{4} / \mathrm{NH}_{3}$ mixtures with a pressure ratio $\left(\mathrm{P}_{\mathrm{NH} 3}: \mathrm{P}_{\mathrm{SiH} 4}\right)$ of $20: 1,50: 1,100: 1$, and 200:1 confirms that the $\mathrm{NH}_{3}$ decomposition is suppressed by the presence of $\mathrm{SiH}_{4}$ molecule in the mixture. This is in agreement with previous studies and explains why a high flow ratio of $\mathrm{NH}_{3}$ to $\mathrm{SiH}_{4}$ is needed under practical deposition conditions to produce silicon nitride thin films. The $\mathrm{NH}_{3}$ decomposition percentage is found to decrease and the time for $\mathrm{N}_{2}$ and $\mathrm{H}_{2}$ to reach their steady-state intensities to increase with increasing $\mathrm{SiH}_{4}$ content in the mixture. This suggests that the extent to which the $\mathrm{NH}_{3}$ decomposition is suppressed is enhanced with more $\mathrm{SiH}_{4}$ in the system. Currently in our laboratory, experiments for a more controlled photoelectron generation is underway for a clear understanding of the LIEI process involved. In addition, our preliminary study has indicated that several possible structures could be responsible for the same mass peak 
observed when trimethylsilane is used as a source gas in a HWCVD reactor. The application of the LIEI source to this more complicated source gas system for positive identification of structure isomers will be explored in the future.

\section{Acknowledgments}

This work was supported by the National Sciences and Engineering Research Council (NSERC) of Canada and the University of Calgary. The authors thank Xinmao Li for his help with the experiments and Dr. Scott Paulson for his help in electron microprobe analysis of the tungsten filaments.

\section{References}

1. Mahan, A. H. An Update on Silicon Deposition Performed by Hot-Wire CVD. Thin Solid Films 2006, 501, 3-7.

2. Liu, F.; Ward, S.; Gedvilas, L.; Keyes, B.; To, B.; Wang, Q.; Sanchez, E.; Wang, S. Amorphous Silicon Nitride Deposited by Hot-Wire Chemical Vapor Deposition. J. Appl. Phys. 2004, 96, 2973-2979.

3. Gallagher, A. Some Physics and Chemistry of Hot-Wire Deposition. Thin Solid Films 2001, 395, 25-28.

4. Tange, S.; Inoue K.; Tonokura, K.; Koshi, M. Catalytic Decomposition of $\mathrm{SiH}_{4}$ on a Hot Filament. Thin Solid Films 2001, 395, 42-46.

5. Doyle, J. D.; Robertson, R.; Lin, G. H.; He, M. Z.; Gallagher, A. Production of High-Quality Amorphous Silicon Films by Evaporative Silane Surface Decomposition. I. Appl. Phys. 1988, 64, 3215-3223.

6. Duan, H. L.; Zaharias, G. A.; Bent, S. F. Probing Radicals in Hot-Wire Decomposition of Silane Using Single Photon Ionization. Appl. Phys. Lett. 2001, 78, 1784-1786.

7. van Veenendaal, P. A. T. T.; Schropp, R. E. I. Processes in Silicon Deposition by Hot-Wire Chemical Vapor Deposition. Curr. Opin. Solid State Mater. Sci. 2002, 6, 465-470.

8. Holt, J. K.; Swiatek, M.; Goodwin, D. G.; Muller, R. F.; Goddard, W. A. III; Atwater, H. A. Gas-Phase and Surface Kinetic Processes in Polycrystalline Silicon Hot-wire Chemical Vapor Deposition. Thin Solid Films 2001, 395, 29-35.

9. Nakamura, S.; Koshi, M. Elementary Processes in Silicon Hot-Wire CVD. Thin Solid Films 2006, 501, 26-30.

10. Grosman, M.; Löffler, D. G. Kinetics of Ammonia Decomposition on Polycrystalline Tungsten. J. Catalysis 1983, 80, 188-193.

11. Butoi, C. I.; Steen, M. L.; Peers, J. R. D.; Fisher, E. R. Mechanisms and Energy Transfer for Surface Generation of $\mathrm{NH}_{2}$ During $\mathrm{NH}_{3}$ Plasma Processing of Metal and Polymer Substrates. J. Phys. Chem. B 2001, 105, 5957-5967.

12. Umemoto, H.; Ohara, K.; Morita, D.; Morimoto, T.; Yamawaki, M.; Masuda, A.; Matsumura, H. Radical Species Formed by the Catalytic Decomposition of $\mathrm{NH}_{3}$ on Heated W Surfaces. Jpn. J. Appl. Phys. Part 1 2003, 42, 5315-5321.

13. Stannowski, B.; Rath, J. K.; Schropp, R. E. I. Growth Process and Properties of Silicon Nitride Deposited by Hot-wire Chemical Vapor Deposition. J. Appl. Phys. 2003, 93, 2618-2625.

14. Umemoto, H.; Morimoto, T.; Yamawaki, M.; Masuda, Y.; Masuda, A.; Matsumura, H. Deposition Chemistry in the Cat-CVD Processes of the $\mathrm{SiH}_{4} / \mathrm{NH}_{3}$ System. Thin Solid Films 2003, 430, 24-27.
15. van den Oever, P. J.; van Helden, J. H.; van Hemmen, J. L.; Engeln, R.; Schram, D. C.; van de Sanden, M. C. M.; Kessels, W. M. M. N, NH, and $\mathrm{NH}_{2}$ Radical Densities in a Remote $\mathrm{Ar}-\mathrm{NH}_{3}-\mathrm{SiH}_{4}$ Plasma and their Role in Silicon Nitride Deposition. J. Appl. Phys. 2006, 100, 093303-1-09330310

16. Wang, Q.; Ward, S.; Gedvilas, L.; Keyes, B.; Sanchez, E.; Wang, S. Conformal Thin-Film Silicon Nitride Deposited by Hot-wire Chemical Vapor Deposition. Appl. Phys. Lett. 2004, 84, 338-340.

17. Matsumura, H. Formation of Silicon-Based Thin Films Prepared by Catalytic Chemical Vapor Deposition (Cat-CVD) Method. Jpn. J. Appl. Phys. 1998, 37, 3175-3186.

18. Shi, Y. J.; Lo, B.; Tong, L.; Li, X.; Eustergerling, B. D.; Sorensen, T. S. In situ Diagnostics of the Decomposition of Silacyclobutane on a Hot Filament by Vacuum Ultraviolet Laser Ionization Mass Spectrometry. J. Mass Spectrom. 2007, 42, 573-583.

19. Li, X. M.; Eustergerling, B. D.; Shi, Y. J. Mass Spectrometric Study of Gas-Phase Chemistry in a Hot-Wire Chemical Vapor Deposition Reactor with Tetramethylsilane. Int. J. Mass Spectrom. 2007, 263, 233-242.

20. Colby, S. M.; Reilly, J. P. Photoemission Electron Impact Ionization in Time-of-Flight Mass Spectrometry: An Examination of Experimental Consequences. Int. J. Mass Spectrom. Ion Processes 1994, 131, 125-138.

21. Mühlberger, F.; Zimmermann, R.; Kettrup, A. A Mobile Mass Spectrometer for Comprehensive On-line Analysis of Trace and Bulk Components of Complex Gas Mixtures: Parallel Application of the Laser-Based Ionization Methods VUV Single-Photon Ionization, Resonant Multiphoton Ionization Laser-Induced Electron Impact Ionization. Anal. Chem. 2001, 73, 3590-3604.

22. Schriemer, D. C.; Li, L. Laser-Induced Surface Ionization in a Time-ofFlight Mass Spectrometer. Rev. Sci. Instrum. 1995, 66, 55-62.

23. Cheng, P. Y.; Dai, H. L. A Photoemitted Electron-Impact Ionization Method for Time-of-Flight Mass Spectrometers. Rev. Sci. Instrum. 1993, 64, 2211-2214.

24. Rohwer, E. R.; Beavis, R.C.; Koster, C.; Lindner, J.; Grotemeyer, J. Schlag, E. W. Fast Pulsed Laser Induced Electron Generation for Electron Impact Mass Spectrometry. Z. Naturforsch. 1988, 43a, 11511153.

25. Boyle, J. G.; Pfefferle, L. D.; Gulcicek, E. E.; Colson, S. D. Laser-Driven Electron Ionization for a VUV Photoionization Time-of-Flight Mass Spectrometer. Rev. Sci. Instrum. 1991, 62, 323-333.

26. Shi, Y. J.; Eustergerling, B. D.; Li, X. M. Mass Spectrometric Study of Gas-Phase Chemistry in the Hot-wire CVD Processes of $\mathrm{SiH}_{4} / \mathrm{NH}_{3}$ Mixtures. Thin Solid Films 2007, 06, 029.

27. Schriemer, D. C.; Li, L. Surface Analysis of Bulk Polymers Using Laser-Induced Photoelectron Ionization with Laser Desorption in a Time-of-Flight Mass Spectrometer. Anal. Chem. 1996, 68, 250-256.

28. Melton, C. E.; Emmett, P. H. Transient Species Observed in the Catalyzed Decomposition of Ammonia, J. Phys. Chem. 1964, 68, 33183324.

29. Stohard, N.; Humpfer, R.; Grotheer, H. The Multichannel Reaction $\mathrm{NH}_{2}$ $+\mathrm{NH}_{2}$ at Ambient Temperature and Low Pressures. Chem. Phys. Lett. $1995,240,474-480$

30. Corchado, J. C.; Espinosa-Garcia, J. Analytical Potential Energy Surface for the $\mathrm{NH}_{3}+\mathrm{H} \leftrightarrow \mathrm{NH}_{2}+\mathrm{H}_{2}$ reaction: Application of Variational Transition-State Theory and Analysis of the Equilibrium Constants and Kinetic Isotope Effects Using Curvilinear and Rectilinear Coordinates. J. Chem. Phys. 1997, 106, 4013-4021.

31. Bagatur'yants A. A. Minushev, A. K. Novoselov, K. P. Safonov, A. A. Umanskii, S. ; Ya.; Vladimirov, A. S.; Korkin, A. Atomistic Simulation of $\mathrm{Si}_{3} \mathrm{~N}_{4}$ CVD from Dichlorosilane and $\mathrm{NH}_{3}$. In Predictive Simulation of Semiconductor Processing: Status and Challenges; Dabrowski, J.; Weber, E. R., Eds.; Springer-Verlag: Berlin, 2004; p 295.

32. Shi, Y. J.; Consta, S.; Das, A. K.; Mallik, B.; Lacey, D.; Lipson, R. H. A 118 $\mathrm{nm}$ Vacuum Ultraviolet Laser/Time-of-Flight Mass Spectroscopic Study of Methanol and Ethanol Clusters in the Vapor Phase. J. Chem. Phys. 2002, 116, 6990-6999. 